\title{
An analysis of non response in HIV testing in India: evidences from National Family Health Survey-3
}

Shri Kant Singh

From $16^{\text {th }}$ International Symposium on HIV and Emerging Infectious Diseases

Marseille, France. 24-26 March 2010

\section{Background}

This paper aims to analyze biases in the community based estimate of HIV prevalence in India due to non-response.

\section{Methods}

It uses NFHS-3 data, where community based HIV prevalence has been derived by testing 103,000 adults as part of national level household survey.

\section{Results}

Analysis of sexual behavior of the respondents in terms of number of sexual partners in the last 12 months, condom use with the last sexual partner and pattern of alcohol consumption portrays relatively lower non response among those reported to indulge in risky sexual behavior. Women and men living in urban areas, completed atleast 10 years of schooling and coming from wealthier households are significantly more likely than their respective counterparts to refuse for HIV testing after participating in the interview. The odds of refusals are 0.5 times less likely among rural women and men $(\mathrm{p}<0.001)$. Adult men reporting two or more sexual partners in the last 12 months and women reporting not using condom in their last sexual encounter are significantly less likely to refuse HIV testing. HIV prevalence is predicted among those who were not tested based on a model of HIV for those who were tested. Separate predictions are made for the "interviewed, not-tested" and "eligible, but not interviewed, not-tested" groups. Adjusted HIV prevalence is calculated as a weighted average of the observed prevalence in the tested group and predicted prevalence in the two non-tested groups. The missed population analysis uses

Correspondence: sksingh1992@yahoo.co.in

International Institute for Population Sciences, Mumbai, India reasonable assumptions about HIV prevalence in the nonhousehold population. Given the low HIV prevalence in the general population, it is highly unlikely that the prevalence in the missed population would exceed 10\%. Even if we assumed that the prevalence rate in the missed population was as high as $10 \%$, HIV prevalence in the total population would increase from $0.3 \%$ to only $0.4 \%$.

\section{Discussion}

On the basis of the adjusted values of these predictors, the hypothesis of relationship between risky sexual behaviour and non response in HIV testing is rejected with 95\% confidence interval and hence the non response to HIV testing in NFHS-3 is not likely to under estimate the HIV prevalence in India.

Published: 11 May 2010

doi:10.1186/1742-4690-7-S1-P135

Cite this article as: Singh: An analysis of non response in HIV testing in India: evidences from National Family Health Survey-3. Retrovirology 2010 7(Suppl 1):P135.

Submit your next manuscript to BioMed Central and take full advantage of:

- Convenient online submission

- Thorough peer review

- No space constraints or color figure charges

- Immediate publication on acceptance

- Inclusion in PubMled, CAS, Scopus and Google Scholar

- Research which is freely available for redistribution

Submit your manuscript at www.biomedcentral.com/submit 